\title{
Clinical Analysis of Hoarseness in Children as Seen in Otorhinolaryngology Department of a Tertiary Health Institution in North-West, Nigeria
}

\author{
Aliyu Daniel*, Amutta Baba Stanley \\ Department of Otorhinolaryngology, Usmanu Danfodiyo University Teaching Hospital, Sokoto, Nigeria \\ Email: "danoaliyu@yahoo.com
}

Received 30 November 2015; accepted 5 March 2016; published 8 March 2016

Copyright (C) 2016 by authors and Scientific Research Publishing Inc.

This work is licensed under the Creative Commons Attribution International License (CC BY).

http://creativecommons.org/licenses/by/4.0/

(c) (i) Open Access

\begin{abstract}
Normal phonation is produced in the larynx by the blast of pulmonic air stream that vibrates the vocal cords. Hoarseness reflects changes in the structure or function of the vocal cords. Objective: This is to describe the clinical profile of hoarseness in children and aetiological factors in a tertiary health institution. Methodology: This is a retrospective eight-year (2006-2013) study of clinical records of patients with hoarseness as their main symptom seen in the ENT department of the Usmanu Danfodiyo University Teaching Hospital Sokoto. Results: Fifty-two children with hoarseness were studied. Thirty three $(63.5 \%)$ were males, while $19(36.5)$ were female with a male: female ratio of 1.7:1. The age range was 1 - 13 years with a mean age of 5.1 years. Age group 4 - 7 years (38.5\%) were observed to be more affected with duration of hoarseness ranging from 1 day to 5 years. RRP $23(44.2 \%)$ was the most common aetiology of hoarseness followed by foreign body $15(28.8 \%)$ and Acute Laryngeal infections 9 (17.3\%). Tracheostomy was done in 29 (55.8\%) of patients. Two patients died post operatively due to improper tracheostomy tube care in the ward. Conclusion: With delayed presentation and its attendant grave sequelae, it has become imperative that persistent hoarseness in children lasting more than three weeks should be endoscopically evaluated by an otorhinolaryngologist.
\end{abstract}

\section{Keywords}

Hoarseness, Children, Recurrent Respiratory Papillomatosis, Tracheostomy

\footnotetext{
"Corresponding author.
}

How to cite this paper: Daniel, A. and Stanley, A.B. (2016) Clinical Analysis of Hoarseness in Children as Seen in Otorhinolaryngology Department of a Tertiary Health Institution in North-West, Nigeria. Open Journal of Pediatrics, 6, 17-21. 


\section{Introduction}

The term Voice is the acoustic outputs from the Larynx that are characterized by their dependence on Vocal cord vibratory inputs [1]-[4]. The quality of the voice is wholly dependent upon the vibratory characteristics of the laryngeal structure [1]. Hoarseness is a Disorder of Voice simply defined as a perceived rough, harsh or breathy quality of the Voice [3]. The disorder reflects changes in the structure and function of the vocal cords, mostly following laryngeal inflammation, trauma, neoplastic lesions or motility disorder of the vocal cords [2] [3].

There is limited information on the prevalence of Voice disorder particularly the pediatric population. The prevalence of hoarseness in children ranges from $4 \%$ - 23\% in the United State of America [3].

Hoarseness in children has varied presentation depending on the etiology and may be transient just like in the adult when due to acute inflammation of the larynx [4]. The tendency of misdiagnosis contributes to the delayed in presentation to otorhinolaryngologist. In our region, medical attention is being sought for when complication of upper airway obstruction has ensued.

The study details the clinical presentation of hoarseness in children in our center and highlights challenges in management.

\section{Materials and Method}

This is a retrospective study of clinical records of patients who primarily presented or were referred to the Ear, Nose and Throat department of the Usmanu Danfodiyo University Teaching Hospital Sokoto, Nigeria with Hoarseness as their main symptom over an Eight-year period ( $1^{\text {st }}$ January 2006 to $31^{\text {st }}$ December 2013). Data extracted from the retrieved health information records of these patients included-biodata, history of difficulty in breathing, onset and duration of hoarseness, history of previous head and neck trauma or surgery and relevant drug medication. There are detail records of radiological and operative findings, and histological diagnosis. Endoscopic laryngeal evaluation was carried out in all patients, while tissue biopsy, and foreign body removal or laryngeal repair were done under general anaesthesia to some patients. The data was analyzed using simple descriptive epidemiology, tables and figures.

\section{Results}

A total of 52 children with hoarseness were analyzed. Thirty three (63.5\%) were males, while 19 (36.5) were female with a Male: female ratio of 1.7:1. The age range was 1 month - 13 years with a mean age of 5.1 years. Age group 4 - 7 years (38.5\%) were observed to be more affected with a duration of hoarseness ranging from 1 day to 5 years.

Recurrent respiratory papilomatosis 23 (44.2\%) was the commonest aetiology of hoarseness followed by Laryngeal foreign bodies 15 (28.8\%) and 9 (17.3\%) Acute laryngeal infections are shown in Table 1 . Tracheostomy was done in 29 (55.8\%) of patients (Figure 1). Of these, 15 (28.8\%) with severe upper airway obstruction at presentation and subsequently had emergency tracheostomy. The other identified causes of hoarseness in this study were trauma 3 (5.8\%) and vocal cord nodules 2 (3.9\%). Two patients died post operatively due to improper tracheostomy tube care in the ward while decanulation and follow up of the 27 (51.9\%) patients were uneventful.

\section{Discussion}

The infantile larynx is proportionally smaller than that of the adult compared to body size and lies opposite the third to sixth cervical vertebrate [1]-[3]. Also being a little high in position than in men [5]. Laryngeal pathology in children more frequently results in the development of upper airway obstruction requiring meticulous clinical evaluation for possible etiology. Hoarseness in children however, depicts laryngeal pathology. In this study, prevalence of hoarseness was observed to be higher in males with a ratio of M:F 1.7:1 and age group 4 - 7 years being commonly affected which agrees with the findings of similar studies in sub-Saharan Africa [4]. The leading cause of childhood hoarseness in our study is recurrent respiratory papilomatosis (Table 1 \& Table 2). This condition has been reported to be the most common benign tumor of the larynx in children [6] [7]. It is a potentially devastating condition with significant morbidity. Human papiloma virus (HPV) type 6 and 11 is responsible for the development of RRP. This virus has been associated with vertical transmission from mother to child during vaginal delivery from an infected mother [8] [9]. RRP affected 23 (44.2\%) of our study population 
Table 1. Age distribution of etiology of hoarseness.

\begin{tabular}{|c|c|c|c|c|c|c|c|}
\hline $\begin{array}{l}\text { Age in } \\
\text { years }\end{array}$ & $\begin{array}{l}\text { Recurrent resp. } \\
\text { pappiloma (RRP) }\end{array}$ & $\begin{array}{l}\text { Foreign } \\
\text { bodies }\end{array}$ & Acute infections & Trauma & $\begin{array}{l}\text { Vocal cord } \\
\text { nodules }\end{array}$ & Total & $\begin{array}{c}\text { Percentage } \\
\%\end{array}$ \\
\hline $0-3$ & 3 & 8 & 5 & 1 & 2 & 19 & $36.5 \%$ \\
\hline $4-7$ & 11 & 5 & 2 & 2 & - & 20 & $38.5 \%$ \\
\hline $8-11$ & 7 & 2 & 2 & - & - & 11 & $21.2 \%$ \\
\hline $12-15$ & 2 & - & - & - & - & 2 & $3.8 \%$ \\
\hline Total & 23 & 15 & 9 & 3 & 2 & 52 & $100 \%$ \\
\hline
\end{tabular}

Table 2. Sex distribution of laryngeal pathology.

\begin{tabular}{|c|c|c|c|}
\hline Laryngeal pathology & Male & Female & Total (\%) \\
\hline \multicolumn{4}{|l|}{ Recurrent respiratory } \\
\hline Pappilomatosis & 16 & 7 & $23(44.2 \%)$ \\
\hline Foreign bodies: & & & $15(28.8 \%)$ \\
\hline - Glass & 2 & - & \\
\hline - $\quad$ Ear rings & 2 & 3 & \\
\hline - Ground nut shell & 2 & 1 & \\
\hline - Toy valve & 1 & 1 & \\
\hline - $\quad$ Screw & 2 & 1 & \\
\hline Acute laryngeal infections: & & & $9(17.3 \%)$ \\
\hline - $\quad$ Croup & 3 & 1 & \\
\hline - $\quad$ Epiglotitis & 1 & 1 & \\
\hline - Retropharyngeal abscess & 2 & 1 & \\
\hline Vocal cord nodules & 2 & - & $2(3.9 \%)$ \\
\hline Laryngeal trauma & 2 & 1 & $3(5.8 \%)$ \\
\hline
\end{tabular}
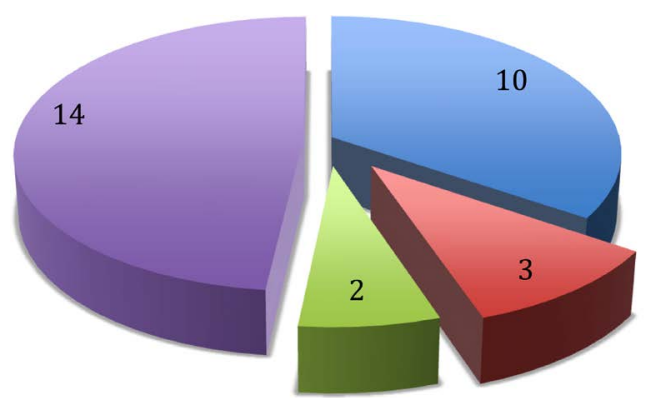

$$
\begin{aligned}
& \text { Foreign Body } \\
& \text { Acute Infection } \\
& \text { Trauma } \\
& \text { RRP }
\end{aligned}
$$

RRP= Recurrent Respiratory Pappillomatosis.

Figure 1. Distribution of patients requiring tracheostomy.

and frequently misdiagnosed as asthma in our region. This is at variance with studies in the developed world, where laryngo-pharyngeal reflux is now the leading cause of childhood hoarseness [10].

Foreign bodies are the second most common cause of hoarseness constituting 28.8\% in our study (Table 1 \& Table 2). Tracheostomy was done in five of these patients pre-operatively due to prolonged impaction resulting in upper airway obstruction. The unusual foreign body in our study was in a nine months old boy with impacted triangular piece of glass in the larynx (Figure 2(a) \& Figure 2(b)). Endoscopic removal of the foreign bodies under general anaesthesia was achieved in all. Children aged 0 - 3 years were commonly affected which is in consonance with earlier studies in sub-Saharan Africa [4]. This is because children in this age group are very inquisitive and still exploring objects in their environment placing them in their mouth more frequently [11]-[13]. This underscores the need for awareness and close monitoring of these children by their parents or caregivers. 


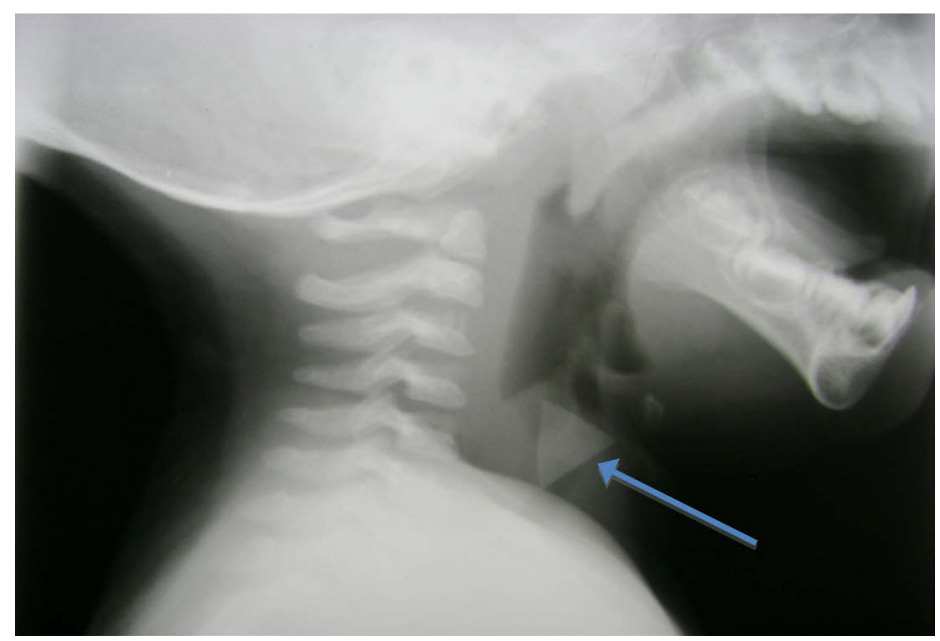

(a)

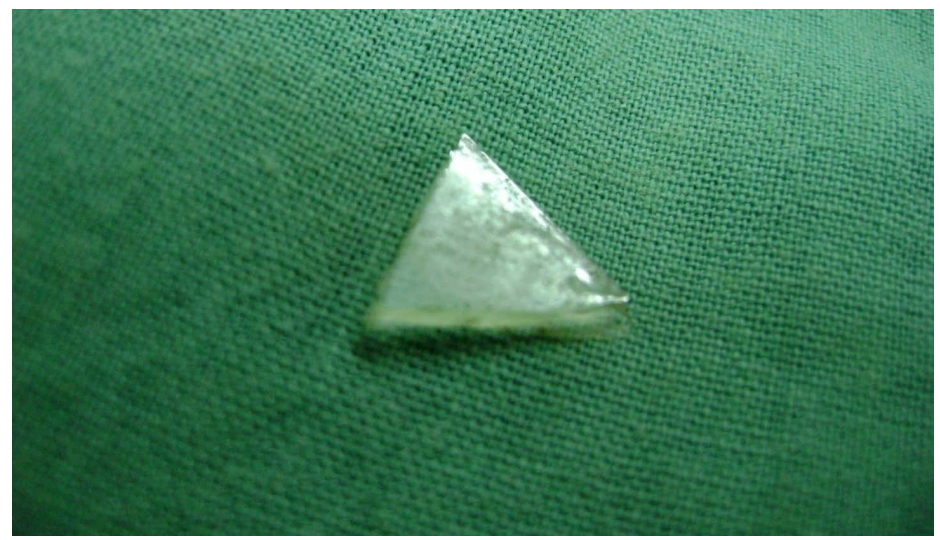

(b)

Figure 2. (a) X-ray Soft tissue neck, Lateral view showing an impacted radiopaque glass foreign body in the larynx of an infant (arrow). (b) Foreign body (glass) removed after direct laryngoscopy under general anaesthesia.

Acute laryngeal infections in our series were, Croup, Epiglottitis and retropharyngeal abscess. There were no records of immunizable diseases in our current report as in similar studies in the region [4]. This is a remarkable improvement in the ongoing health education on Vaccines immunization against Childhood diseases. All had remarkable improvement after doses of broad-spectrum penicillin based antibiotics. The retropharyngeal abscess which commonly followed rupture of retropharyngeal lymph node was drained under general anaesthesia. Plain radiographs of the soft tissue neck are an invaluable tool in the diagnosis of this condition.

The aggressiveness of children in their natural habitat makes them prone to trauma and this accounted for $5.8 \%$ of our study population.

Hoarseness following vocal cord nodules (the most common cause of dysphonia in children) [4] is less common and is observed in 3.9\% of our patients and similar to previous reports in the region [4] [14]. This could be the less vigorous use of the voice by children.

Patients with laryngeal pathology requiring a tracheostomy following laryngeal obstruction accounted for $55.8 \%$ of our study population (Figure 1). The high frequency is in consonance with findings in earlier studies [15] [16] and could be attributed to late presentation to otorhinolaryngologist.

\section{Conclusions}

Recurrent respiratory papillomatosis is the leading cause of hoarseness in children in sub-Saharan Africa, hence the need for other adjuvant methods of treatment to achieve complete remission is recommended.

Early presentation of a child with hoarseness will improve the quality of life. We also recommend that persis- 
tent hoarseness in children lasting more than three weeks should be endoscopically evaluated by an otorhinolaryngologist.

\section{Disclosure}

The authors declare that there is no conflict of interest regarding the publication of this paper.

\section{References}

[1] Jean-Pierre, J. and Marcelle, M. (2008) Assessment and Examination of the Upper Respiratory Tract. In: Scott-Browns Otorhinolaryngology, Head and Neck Surgery, Vol. 2, 7th Edition, Horder Arnolds Publishers, London, 2145-2152.

[2] Schwartz, S.R., Cohen, S.M. and Dailey, S.H. (2009) Clinical Practice Guidance; Hoarseness (Dysphonia). Otolaryngology_Head and Neck Surgery, 7, 458-460.

[3] Duff, M., Proctor, A. and Yairi, E. (2004) Prevalence of Voice disorders in African American and European American Preschoolers. Journal of Voice, 18, 348. http://dx.doi.org/10.1016/j.jvoice.2003.12.009

[4] Ben, H. (2008) Peadiatric Voice Disorder. In: Scott-Browns Otorhinolaryngology, Head and Neck Surgery, Vol. 1, 7th Edition, Horder Arnolds Publishers, London, 1167-1172.

[5] Nwaorgu, O.G.B., Mgbor, N.C., Onakoya, P.A., Ayodele, K.J. and Ibekwe, T.S. (2004) Hoarseness in Children: Clinical Spectrum as Seen in the Otorhinolaryngology Department of Two Nigerian Tertiary Health Institutions. Nigeria Journal of Otorhinolaryngology, 1, 6-10.

[6] Nigel, B. (2008) Anatomy of the Larynx and Tracheobronchial Tree. In: Scott-Browns Otorhinolaryngology, Head and Neck Surgery, Vol. 2, 7th Edition, Horder Arnolds publishers. London, 2130-2144.

[7] Shah, K.V., Stern, W.F. and Shah, F.K. (1998) Risk Factors for Juvenile Onset of Recurrent Respiratory Papillomatosis. Pediatric Infectious Disease Journal, 17, 372-376. http://dx.doi.org/10.1097/00006454-199805000-00005

[8] Derkay, C.S. and Wiatrack, B. (2008) Recurrent Respiratory Papillomatosis: A Review. Laryngoscope, $118,1236$. http://dx.doi.org/10.1097/MLG.0b013e31816a7135

[9] Nwaorgu, O.G.B., Bakari, A.A., Onakoya, P.A. and Ayodele, K.J. (2004) Recurrent Respiratory Papillomatosis in Ibadan, Nigeria. Nigerian Journal of Medicine, 13, 235-238.

[10] Stamataki, S., Nikolopoulos, T.P., Korres, S., Felekis, D., Tzangaroulakis, A. and Ferekidis, E. (2007) Juvenile Recurrent Respiratory Papillomatosis Still a Mystery Disease with Difficult Management. Head and Neck, 29, 156-162. http://dx.doi.org/10.1002/hed.20491

[11] Block, B.B. and Brodsky, L. (2007) Hoarseness in Children: The Role of Laryngopharyngeal Reflux. International Journal of Pediatric Otorhinolaryngology, 1, 1361-1369.

[12] Okafor, B.C. (1976) Foreign Body in the Larynx: Clinical Features and a Plea for Early Referral. Nigerian Medical Journal, 6, 470-472.

[13] Iseh, K.R., Abdullahi, M. and Aliyu, D. (2008) Laryngo-Tracheo-Bronchial Foreign Bodies: Indication for Endoscopic Evaluation of Sudden or Persistent Respiratory Symptoms. Sahel Medical Journal, 11, 97-101.

[14] Aliyu, D., Iseh, K.R., Abdullahi, M. and Amutta, S.B. (2013) Clinical profile of Paediatric Pharyngo-Oesophageal Foreign Bodies in a Tertiary Health Institution, North-West Nigeria. Caliphate Medical Journal, 1, 8-12.

[15] Ogunleye, A.O.A., Nwaorgu, O.G.B. and Sogebi, O.A. (2001) Upper Airway Obstruction in Nigeria: An Etiological Profile and Review of the Literature. Tropical Doctor, 31, 195-197.

[16] Aliyu, D., Iseh, K.R., Abdullahi, M., Amutta, S.B. and Yikawe, S.S. (2013) Tracheostomy in Sokoto, North Western Nigeria: A Ten Years Experience. Caliphate Medical Journal, 1, 22-27. 